\title{
A Questionnaire Based Study on the Concepts of Protein Supplementation in Exfoliative Dermatitis Among Dermatologists
}

\author{
Gangadharan $\mathbf{G}^{\mathbf{1}}$, Criton $\mathbf{S}^{2}$, Nazeer $\mathbf{M}^{3}$ \\ ${ }^{1}$ Junior Resident, ${ }^{2}$ Professor \& ${ }^{3}$ Assistant Professor; Department of Dermatology Venereology, Amala Institute of \\ Medical Sciences, Thrissur, Kerala, India
}

\begin{abstract}
Introduction: The impact of exfoliative dermatitis on protein metabolism results in a negative nitrogen balance, but the exact turnover of plasma proteins in this situation is not known. Timely addressing of this metabolic response to exfoliation is crucial in its management.

Objectives: To study the understanding on the concept of protein supplementation in cases of exfoliative dermatitis, among dermatologists.

Material and methods: A cross sectional questionnaire based survey study was conducted among dermatologists who attended annual state conference of IADVL, Kerala chapter. Analysis was based on responses to the questionnaire by 51 practicing dermatologists who had answered and returned the questionnaire, out of the total 84 who were approached for the study. Responses to questions from the interviews were summarized and expressed as numbers and percentages.

Results: Majority $(32,62.7 \%)$ of the dermatologists attributes chronicity of illness to the severity of protein loss in exfoliative dermatitis. Though serum albumin level is considered as the criterion for protein supplementation, opinion regarding the frequency of estimation, mode and end point of supplementation varies. The majority $(36,70.6 \%)$ of dermatologists regards protein supplementation as mandatory in all cases of exfoliative dermatitis and that it helps in recovery of the condition, irrespective of etiology.

Limitation: The small sample size is an obvious limitation

Conclusion: Lack of a clear consensus and knowledge regarding the turnover of plasma proteins in exfoliative dermatitis and the correction of hypoalbuminemia, is clearly portrayed by our results. Further studies are needed to explore the exact pathophysiology of metabolic response to exfoliation and to fill the gaps in the understanding of the same.
\end{abstract}

Key words: Exfoliative dermatitis, Protein loss, Hypoalbuminemia

\section{Introduction}

E xfoliative dermatitis or erythroderma, first described by Von Hebra in 1868 , is an inflammatory disorder of skin characterized by generalized redness and scaling of skin involving more than $90 \%$ of the body surface area. Even with an estimated annual incidence of 35 cases per 1,00,000 dermatology outpatient visits representing $1-1.5 \%$ of total skin clinic admissions ${ }^{1-4}$, the exact etiology and overall management of exfoliative dermatitis often stands challenging. There

\section{Address for correspondence}

Dr. Geethu Gangadharan

Department of Dermatology Venereology,

Amala Institute of Medical Sciences

Amala Nagar, Thrisssur , 680555, Kerala

Email: drgeethugangadharan@gmail.com exists a number of gaps in the understanding of the metabolic effects of exfoliative dermatitis and its correction.

The metabolic response to exfoliation and its effect on nitrogen balance was studied with great enthusiasm in the past. It was observed that patients with exfoliative dermatitis develop the stigmata of negative nitrogen balance-edema, hypoalbuminemia, and loss of muscle mass. ${ }^{5}$ The disturbance in protein metabolism in exfoliative dermatitis usually occurs due to protein lost from the skin and gastrointestinal tract, due to malabsorption, increased catabolism, decreased synthesis and decreased intake of protein. According to the study by Freedberg and Baden, exfoliation more than $17 \mathrm{~g} / \mathrm{m}^{2} /$ day can lead to a negative nitrogen balance. ${ }^{3}$ Later, Kanthraj et al observed that exfoliative 
dermatitis may increase the daily protein loss by approximately $25-30 \%$ in psoriasis and by $10-15 \%$ in exfoliative dermatitis due to other causes. Based on this observation, they recommend early supplementation of protein, in addition to the normal balanced diet, for minimizing the negative nitrogen balance. ${ }^{4}$

The concepts of protein supplementation and monitoring, and the relevance given to the same varies among practitioners. In our daily clinical practice we come across the situation of hypoalbuminemia in exfoliative dermatitis, but the severity of hypoalbuminemia and its response to protein supplementation varies. The primary etiology, chronicity of illness and inter individual variations may be the key players in such situation, but the exact turnover of proteins in exfoliative dermatitis is far from known. Also, the tally of mortality caused due to these metabolic complications calls for the unmet need for a standardization in the monitoring of protein levels and mode of its supplementation in cases of exfoliative dermatitis. This is our pioneer venture to study the understanding regarding the concepts of protein supplementation in exfoliative dermatitis among dermatologists of Kerala. We hope that this may pave way to future research in these not so frequently pondered areas.

\section{Material and methods}

This was a cross sectional questionnaire based survey study conducted among practicing dermatologists of Kerala, India, conducted at the venue of annual conference of IADVL Kerala chapter, held on $9^{\text {th }}$ and $10^{\text {th }}$ of May 2015, in agreement with local regulations. A structured questionnaire on protein loss and supplementation in cases of exfoliative dermatitis was distributed among the dermatologists who attended the conference.

\section{Statistical analysis}

The responses to various questions were tabulated and statistical analysis was done using SPSS 17.0 software. Responses to questions from the interviews were summarized and expressed as numbers and percentages.

\section{Results}

A total of 84 dermatologists were approached, $51(60.7 \%)$ responded and completed the questionnaire, while 33(39.3\%) were non responders. Among the 51 responders, 15 (29.4\%) were in institutional practice,
$14(27.4 \%)$ in private practice and $21(41.2 \%)$ has both institutional and private practice. Majority $(17,33.3 \%)$ of them comes across a case of exfoliative dermatitis once in a month, 15 (29.4\%) once in a week, 12 (23.5\%) once in 2 weeks and 7 (13.25\%) of them rarely see a case of exfoliative dermatitis.

\section{Concepts on gravity of protein loss}

Majority of dermatologists $(32,62.7 \%)$ considers that amount of protein lost in cases of exfoliative dermatitis is related to the chronicity of illness, whereas 10 $(19.6 \%)$ attributes it to the primary etiology and the rest $8(15.7 \%)$ practitioners regards that both etiology and chronicity contributes to the severity of protein loss. (Figure 1) Exfoliative dermatitis secondary to psoriasis was reported to have the most severe protein loss by the majority $(35,68.6 \%)$, but for few $(8,15.7 \%)$ exfoliative dermatitis secondary to internal malignancy had the maximum protein loss. Other etiologies mentioned where atopic dermatitis, contact dermatitis and use of ayurvedic medicines.

\section{Concepts on monitoring of protein levels}

Serum albumin level is considered as the criterion for determining the amount of protein to be supplemented by $34(66.7 \%)$ dermatologists and the majority (37, 72.5\%) estimates serum albumin levels in cases of exfoliative dermatitis. But for $11(21.56 \%)$ dermatologists amount to be supplemented is fixed in all cases and $6(11.7 \%)$ considers that clinical severity determines the amount of protein to be supplemented. (Figure2)

Among the $14(27.5 \%)$ dermatologists who does not regularly estimate serum albumin levels, 6(42.8\%) were not aware of its importance, $4(28.57 \%)$ considers it not important to estimate albumin, as they plan to supplement anyway and 1 (7.1\%) considers it not cost effective to monitor serum albumin levels. Another 3 dermatologists had left the question unanswered.

The frequency of estimation of serum albumin levels varies in the study population, majority(16, 43.2\%) monitors serum albumin level every 2 weeks,11 (29.7.5\%) of them does the estimation every 4 weeks. Monitoring of serum albumin level is done weekly and every 3 weeks by $5(13.5 \%)$ each. (Figure 3 ) 


\section{Concepts on protein supplementation}

Food based protein supplementation is preferred by 18 (35.2\%) dermatologists, $13(25.4 \%)$ prefers protein powder, while $13(25.4 \%)$ favors both food based and protein powder. In cases with serum albumin levels $\leq$ $2 \mathrm{~g} / \mathrm{dl}$, the most preferred mode of supplementation is parenteral $(31,60.8 \%)$, but $12(23.5 \%)$ prefers oral supplementation itself.

Regarding the duration of protein supplementation, majority $(23,45.1 \%)$ gives supplementation till there is documented normal serum albumin level, 9(17.6\%) of them considers arrest of exfoliative dermatitis as end point for supplementation, $5(9.8 \%)$ of them considers both, 6(11.7\%) stops supplementation at some arbitrary time and the rest states various reasons like clinical improvement, when scales and edema decreases or when patient is assessed as clinically stable.

The majority $(36,70.6 \%)$ of dermatologists regards protein supplementation as mandatory in all cases of exfoliative dermatitis and $33(64.7 \%)$ of them observed that protein supplementation will help in recovery of the condition, irrespective of the etiology. But there are a few who disagrees this argument. (Table 1)

Table 1: Distribution of study population based on their concepts regarding protein supplementation in exfoliative dermatitis

\begin{tabular}{|c|c|}
\hline Preferred mode of protein supplementation & Number of Dermatologists (\%) \\
\hline Food based protein supplementation & $18(35.2 \%)$ \\
\hline Protein powder & $13(25.4 \%)$ \\
\hline Both food based and protein powder & $13(25.4 \%)$ \\
\hline Endpoint of protein supplementation & $23(45.1 \%)$ \\
\hline Till there is documented normal serum albumin level & $9(17.6 \%)$ \\
\hline Arrest of exfoliative dermatitis as end point & $5(9.8 \%)$ \\
\hline Both & $6(11.7 \%)$ \\
\hline At some arbitrary time & \\
\hline
\end{tabular}

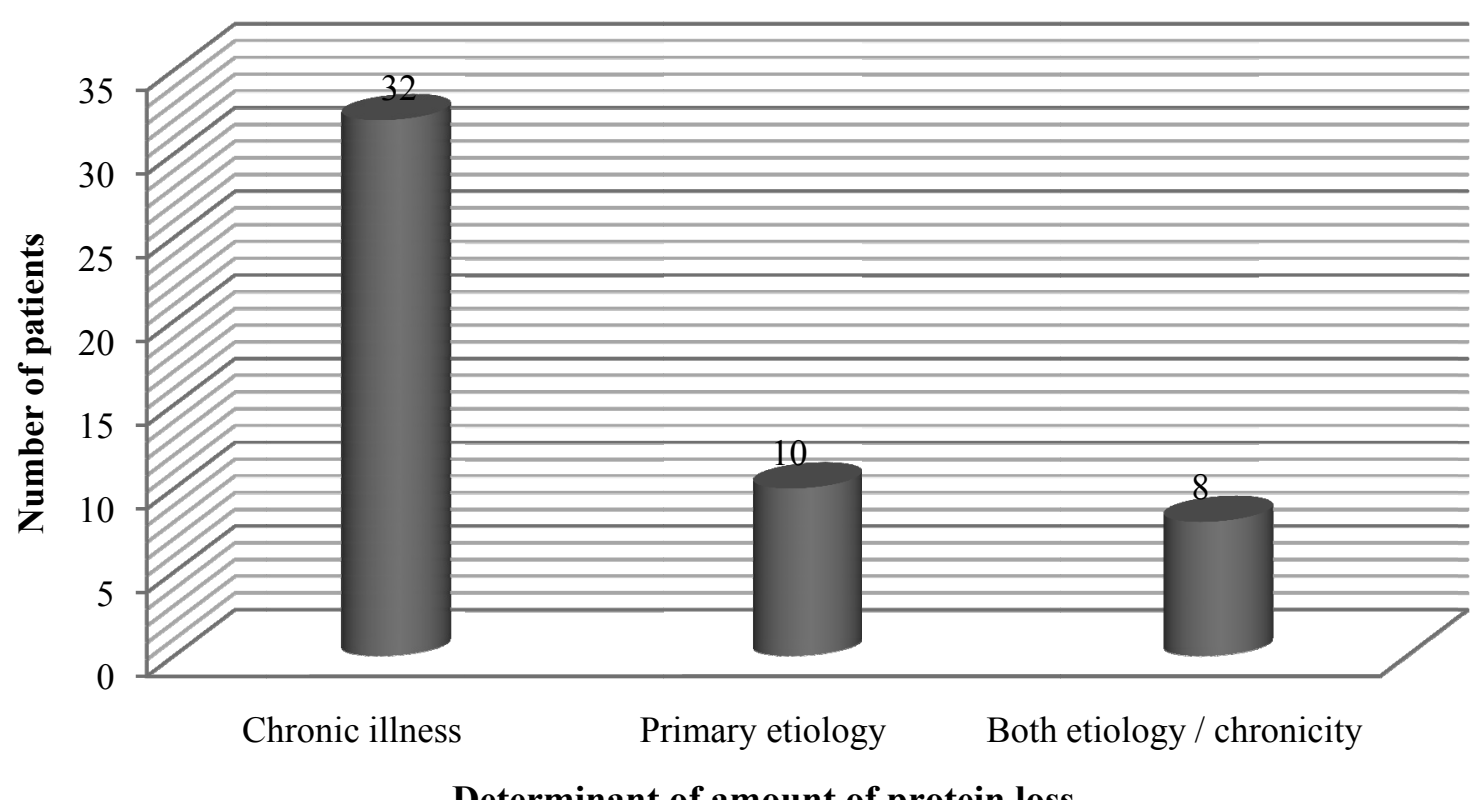

Determinant of amount of protein loss

Figure 1: Distribution of study population based on their concepts on determinants of amount protein loss in cases of exfoliative dermatitis 


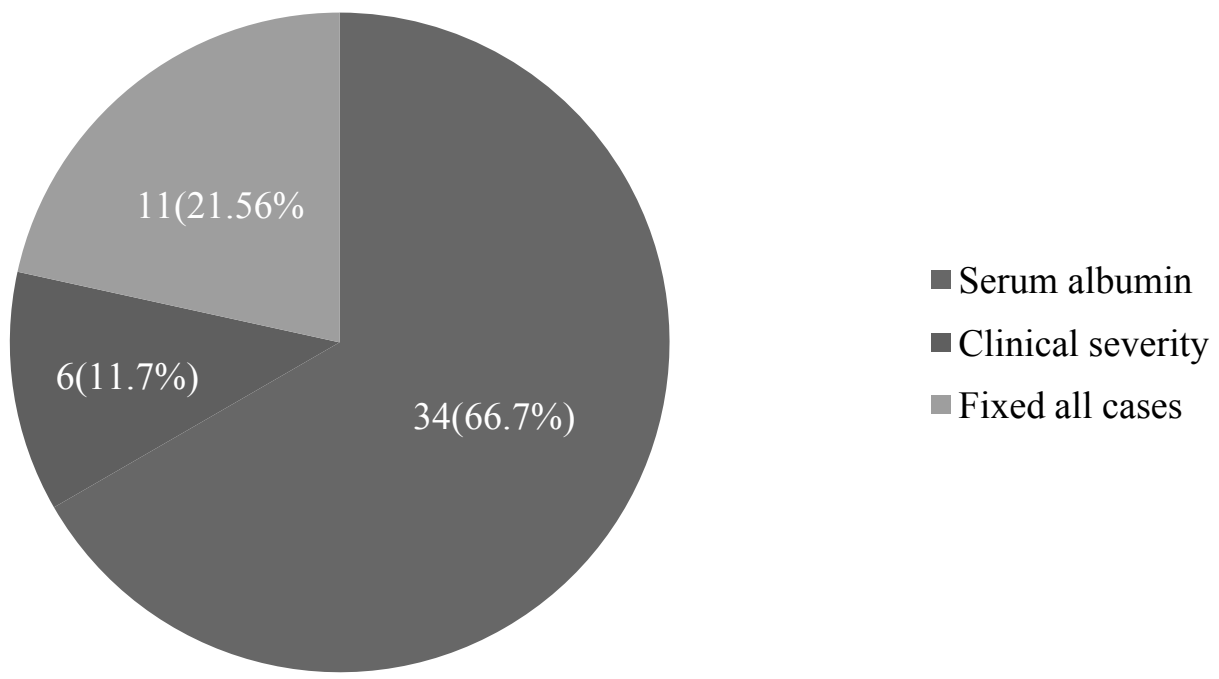

Figure 2: Percentage distribution of the study population based on the factor determining protein supplementation in cases of exfoliative dermatitis

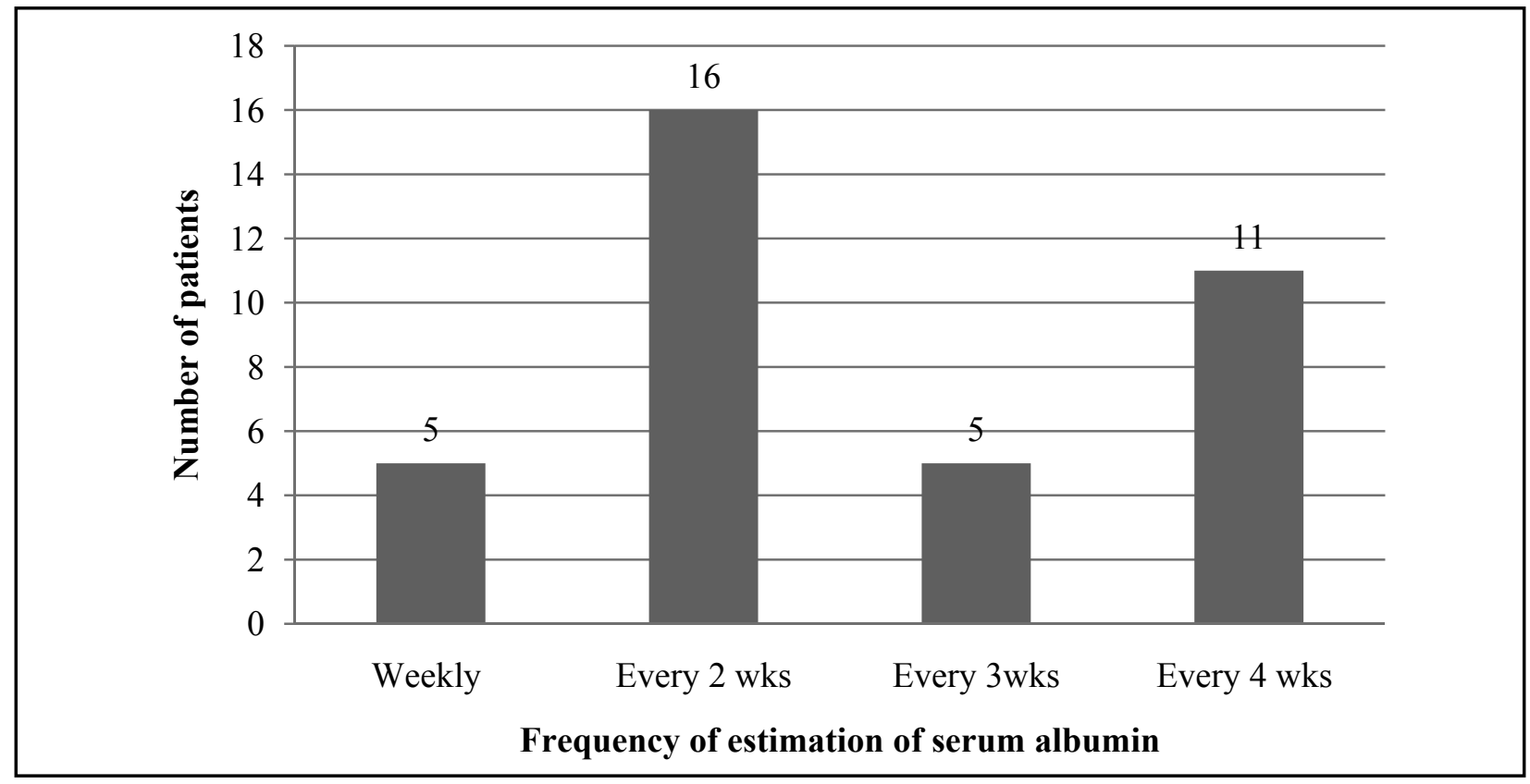

Figure 3: Distribution of study population based on the frequency of estimation of serum albumin in cases of exfoliative dermatitis

\section{Discussion}

The relevance given to metabolic response to exfoliation varies among dermatologists. Though most of the practitioners consider that protein supplementation is mandatory and practices so based on serum albumin level estimation, $25.5 \%$ does not consider it mandatory. Interestingly, 27.5\% agreed that serum albumin levels are not estimated regularly due to either lack of awareness or importance or as it is not cost effective. The frequency of estimation of serum albumin levels also varies widely, but majority considers biweekly estimation as ideal. We have observed hesitancy for parenteral supplementation among some dermatologists $(23.5 \%)$, even when serum albumin levels are less than $2 \mathrm{~g} / \mathrm{dl}$. There exists a difference in opinion also regarding the end point of protein supplementation. 
The concepts regarding various aspects of protein supplementation in exfoliative dermatitis varies widely among dermatologists. This might be due to our oversight of importance of protein supplementation, lack of awareness or due to the still unfilled gaps in turnover of proteins. Though the management of protein supplementation in exfoliative dermatitis is often argued to be individualized, a further research in this aspect will help in better patient care. The small sample size is an obvious limitation of our study. But the alarming variation in concepts, points to the fact that this population may be considered to speak for the unrepresented lots.

\section{Conclusion}

Irrespective of primary etiology, monitoring of serum albumin levels and protein supplementation are held with importance by majority of the dermatologists. But, the lack of a definite protocol or awareness is evidently portrayed by our results. The utmost need for a concensus statement and guidelines for the overall management of metabolic disturbance in exfoliative dermatitis is clearly established from the results of our study. Hence, unfolding the mystery of exact pathophysiology of protein metabolism and turnover of plasma protein proteins in exfoliative dermatitis is the need of the hour.

\section{References}

1. Sehgal VN, Srivastava G, Sardana K. Erythroderma/ Exfoliative dermatitis: a synopsis. Int J Dermatol 2004; 43: 3947. http://dx.doi.org/10.1111/j.13654632.2004.01975.x

2. Bharatiya PR, Joshi PB. Study of exfoliative dermatitis. Indian J Dermatol Venereol Leprol 1995; 61: 81-3.

3. Okoduwa C, Lambert WC, Schwartz RA, Kubeyinje E, Eitokpah A, Sinha $S$, et al. Erythroderma : Review of a potentially life -threatening dermatosis. Indian J Dermatol 2009; 54: 1-6. http://dx.doi.org/10.4103/00195154.48976
4. Sehgal VN, Srivastava G. Exfoliative dermatitis - a prospective study of 80 patients. Dermatologica 1986; 173: 278-84. http:// dx.doi.org/10.1159/000249271

5. Freedberg IM, Baden HP. The metabolic response to exfoliation. J Invest Dermatol 1962; 38: 277-84. http://dx.doi.org/10.1038/ jid. 1962.50

6. Kanthraj GR, Srinivas CR, Devi PU, Ganasoundari A, Shenoi SD, Deshmukh RP et al. Quantitative estimation and recommendations for supplementation of protein lost through scaling in exfoliativedermatitis. Int J Dermatol 1999; 38: 91-5. http://dx.doi.org/10.1046/ j.1365-4362.1999.00408.x 